\title{
Antimicrobial Resistance: Physicians' and Pharmacists' Perspective
}

\author{
Doris Rusic, Josko Bozic, ${ }^{2}$ Josipa Bukic, Marino Vilovic, ${ }^{1}$ Marion Tomicic,, Ana Seselja Perisin, \\ Dario Leskur, Darko Modun, Tin Cohadzic, ${ }^{2}$ and Sinisa Tomic ${ }^{1,4}$
}

\begin{abstract}
Aims: The aim of this study was to evaluate pharmacists' and physicians' attitudes and knowledge about antimicrobial treatment and resistance and based on the results to identify possible gaps and suggest opportunities for collaboration between the two professions.

Methods: The physician's questionnaire consisted of 47 items and the pharmacists' questionnaire consisted of 50 items. Participants were asked to identify situations in which they were more likely to prescribe/dispense an antimicrobial without a firm indication, to identify the greatest contributors to antimicrobial resistance (AMR) among health care workers, to rate statements related to AMR, how frequently they used different sources of information and to rate the possible causes of AMR. Furthermore, preparedness for specific actions in practice was self-rated and knowledge was evaluated. The questionnaires were anonymous and participation in the study was voluntary.

Results: This research included 180 community pharmacists and 181 physicians. As many as $76(42.0 \%)$ physicians stated they would prescribe an antimicrobial when unsure whether the infection was of viral or bacterial etiology. More than half of the participants considered family medicine doctors the greatest contributors to AMR $(N=216,59.8 \%)$, followed by patients $(N=175,48.5 \%)$. In questions focusing on knowledge, physicians scored significantly higher compared with pharmacists $(4.06 \pm 1.01$ vs. $3.71 \pm 1.08, p=0.001)$.

Conclusion: This research revealed practices among pharmacists and physicians that should be improved and it highlighted gaps in knowledge by both professions. More attention should be given to patient consultation when dispensing and prescribing an antimicrobial as this may reduce their contribution to AMR.
\end{abstract}

Keywords: microbial drug resistance, survey, pharmacist, physician, attitudes, knowledge

\section{Introduction}

I n 2019, World Health Organization outlined antimicrobial resistance (AMR) as one of the 10 top threats to global health, alongside air pollution and climate change, noncommunicable diseases, vaccine hesitancy, HIV, and others. ${ }^{1}$ The magnitude of this threat may be illustrated with the following numbers: 700,000 deaths per year worldwide in 2014 attributable to AMR and are estimated to reach 10 million per year worldwide by 2050 . In comparison, cancer is estimated to account for 8.2 million of deaths worldwide in $2050 .^{2}$

Abuse of antimicrobials can lead to increased spread of resistant microbial strains. ${ }^{3}$ Antibiotic misuse coupled with a growing AMR has led to ineffective treatment of common infections, a number of strategies are needed to tackle this growing problem. ${ }^{4}$ For example, $81 \%$ of antibiotics in England are prescribed in a primary care setting and are more likely to progress during the COVID-19 pandemic as a result of remotely overprescribed broad-spectrum antibiotics. ${ }^{5}$ The goal of the updated United Kingdom antibiotic stewardship policies was to significantly change the role of primary care dispensing. ${ }^{6}$

Recent studies have raised question about the ability of physicians to follow guidelines due to the limited availability of appropriate drug packs. ${ }^{7,8}$ This stresses the importance of different skills needed among physicians and an ever-growing need for new and up-to-date information and education. Furthermore, with most of the antibiotic consumption being in primary care, ${ }^{9}$ pharmacists have a unique opportunity to contribute to the management of AMR as well to affect patients' adherence to treatment and management of leftover antimicrobials. Moreover, recently some authors have raised concerns that the COVID-19 pandemic may aggravate and accelerate the emergence of AMR..$^{10,11}$

Departments of ${ }^{1}$ Pharmacy, ${ }^{2}$ Pathophysiology, and ${ }^{3}$ Family Medicine, University of Split School of Medicine, Split, Croatia

${ }^{4}$ The Agency for Medicinal Products and Medical Devices, Zagreb, Croatia. 
To help restrain AMR and promote responsible use of antimicrobials, antimicrobial stewardship programs have been successfully implemented in many countries. The antimicrobial stewardship team should be multidisciplinary, and include specialists and pharmacists. Pharmacists participate in approval of antimicrobials before they are prescribed and counsel on the use of restricted antimicrobials while prescribers are encouraged to make accurate diagnosis, follow local antimicrobial guidelines, and regularly review the need for therapy. ${ }^{12,13}$ Antimicrobial stewardship program implementation in primary care settings can reduce broad-spectrum antimicrobial use. ${ }^{14}$

As studies keep identifying potentially inappropriate antimicrobials prescribed with duration of treatment outside of guideline-based range, ${ }^{15}$ more collaboration among physicians and community pharmacists and greater involvement of community pharmacists in antimicrobial stewardship programs should be encouraged. This study included community pharmacists, family medicine other physicians. The aim of this study was to evaluate pharmacists' and physicians' attitudes and knowledge about antimicrobial treatment and resistance and based on the results to identify the possible gaps and suggest opportunities for collaboration of the two professions.

\section{Methods}

The questionnaire used in the study was adopted from a previously published research conducted among pharmacy and medical students. ${ }^{16}$ This questionnaire was further adjusted for both pharmacists' and physicians' profession according to expected actions in practice according to other published studies covering similar topics. ${ }^{17-21}$ Two pharmacists and two medical doctors evaluated the appropriateness of final version of the questionnaire for both medical doctors and pharmacists working in Croatia.

The questionnaire for physicians consisted of 47 items. The first part questioned participants' level of training, work experience, and situations in which they were more likely to prescribe an antimicrobial drug. Furthermore, participants were asked to identify, in their opinion, the most significant contributors to the emergence of AMR among health care workers. The second part consisted of 15 statements related to AMR rated on a 5-point Likert scale (strongly disagree to strongly agree). In the third section, participants were asked to rate how frequently they used seven different sources of information and to rate the importance of five possible causes of AMR on a 4-point Likert scale (never to often, and not important at all to very important). In the following section, participants were asked to rate their preparedness for seven specific actions in practice on a 5-point Likert scale (poor to very well). Lastly, knowledge was evaluated with 6 true/false statements.

The questionnaire for pharmacists consisted of 50 items. Knowledge questions, most significant contributors to the emergence of AMR among health care workers, possible causes of AMR, and sources of information were equivalent to those in the questionnaire for physicians. However, actions in practice were reduced and correction of antimicrobial dose was introduced for pharmacists. Furthermore, this questionnaire included two additional statements related to AMR specific for pharmacist's profession and a question how often the pharmacists discussed five specific topics with patients when dispensing an antimicrobial drug. Also, pharmacists were asked about situations in which they were more likely to dispense an antimicrobial without a valid prescription.

Both questionnaires were pilot-tested for readability and length among 10 physicians and pharmacists. The questionnaires were anonymous and participation in the study was voluntary. Reading time did not exceed 15 minutes. The questionnaire was distributed in the work place of participants in person or through e-mail. Participants received no compensation for their contribution to the study.

Physicians that were considered eligible for inclusion in the study were those that prescribed antimicrobials in daily practice (i.e., residents and specialists of pediatrics, internal medicine, surgery, and family medicine general physicians). All pharmacists who were offered participation in the study and who participated in the study were community pharmacists. To preserve the anonymity of questionnaire and to avoid providing socially desired answers, all data about the location of the pharmacy and the ownership structure of the pharmacy (county-public or private) were omitted.

The study was approved by The Ethics Committee of the University of Split School of Medicine; IRB approval number: 2181-198-03-04-17-0010. It was conducted from September of 2019 until January 2020 (before the emergence of COVID-19 pandemic in Croatia).

Before analysis, Likert-scale answers were condensed into three categories (strongly agree/agree, not sure, disagree/ strongly disagree and very poor/poor, average well/very well) or two categories (never/rarely, sometimes/often, and not important at all/slightly important, moderately important/very important) where appropriate. Statistical analysis was conducted using MedCalc software for Windows (v. 19.1.2; MedCalc Software, Ostend, Belgium). Results are presented as numbers (proportions) or mean \pm standard deviation where appropriate. Chi-square test or Fisher's exact test where appropriate was used to determinate the differences among pharmacists' and physicians' attitudes, Kolmogorov/Smirnov test was used to evaluate the normality of distribution of data, and $t$ test to evaluate differences in their knowledge. The statistical significance level was set at $p<0.05$ level.

\section{Results}

This research included 180 community pharmacist and 181 physicians working at the University Hospital of Split or at the Health Center of Split-Dalmatia County. This study included $91(53.6 \%)$ residents and $84(46.4 \%)$ specialists, most of which were at pediatrics $(43,23.8 \%)$ followed by $42(23.2 \%)$ residents or specialists of family medicine and $13(7.2 \%)$ residents or specialists of various branches of surgery (abdominal, vascular, children's) and $10(5.5 \%)$ residents or specialists of gastroenterology. There were 12 (6.6\%) physician assistant professors and $3(1.7 \%)$ full professors. Among pharmacists, $11(6.1 \%)$ had specialist training (2 semester postgraduate specialist studies, academic title University Master) and 1 was a specialist (Table 1).

\section{Reasons for prescribing/dispensing an antimicrobial when not indicated}

Reasons why physicians are more likely to prescribe an antimicrobial without a firm indication and why pharmacists 
Table 1. Study Participants Characteristics

\begin{tabular}{lcc}
\hline & $\begin{array}{c}\text { Physicians } \\
(\mathrm{N}=181)\end{array}$ & $\begin{array}{c}\text { Pharmacist } \\
(\mathrm{N}=180)\end{array}$ \\
\hline $\begin{array}{l}\text { Men } \\
\text { Residents }\end{array}$ & $62(34.3 \%)$ & $20(11.1 \%)$ \\
Specialist training & $91(53.6 \%)$ & $\mathrm{n} / \mathrm{a}$ \\
$\quad$ for pharmacists & $\mathrm{n} / \mathrm{a}$ & $11(6.1 \%)$ \\
Specialists & & \\
Departments & $84(46.4 \%)$ & $1(0.6 \%)$ \\
$\quad$ Pediatrics & $43(23.8 \%)$ & $\mathrm{n} / \mathrm{a}$ \\
Family medicine & $42(23.2 \%)$ & $\mathrm{n} / \mathrm{a}$ \\
Surgery & $13(7.2 \%)$ & $\mathrm{n} / \mathrm{a}$ \\
Gastroenterology & $13(7.2 \%)$ & $\mathrm{n} / \mathrm{a}$ \\
Other & $29(16.0 \%)$ & $\mathrm{n} / \mathrm{a}$ \\
Did not state department & $41(22.7 \%)$ & $\mathrm{n} / \mathrm{a}$ \\
Masters of science & $10(5.5 \%)$ & $0(0 \%)$ \\
PhD & $10(5.5 \%)$ & $0(0 \%)$ \\
Assistant professors & $12(6.6 \%)$ & $0(0 \%)$ \\
Full professors & $3(1.7 \%)$ & $0(0 \%)$ \\
\hline
\end{tabular}

Results are presented as numbers (proportions).

anternal medicine, cardiology, nephrology, oncology, dermatology, and emergency medicine.

n/a, not applicable.

are more likely to dispense an antimicrobial without a valid prescription are given in Table 2. Most physicians and pharmacists stated they prescribe or dispense antimicrobials only with a firm indication or with a valid prescription. As many as $76(42.0 \%)$ physicians stated they would prescribe an antimicrobial when unsure whether the infection was of viral or bacterial etiology. In other reasons, 4 (2.2\%) physicians prescribed antimicrobials when demanded by patients, $1(0.6 \%)$ to oncology patients, and $1(0.6 \%)$ to immunocompromised or patients with chronic illnesses. Among other reasons, 14 (7.8\%) pharmacists stated they dispensed antimicrobials with a specialist's report only, 7 $(3.9 \%)$ with a phone recommendation of a physician, 6 $(3.3 \%)$ to a tourist, patients with an upcoming trip or when the patient is unable to get a prescription, $4(2.2 \%)$ to family and friends, $3(1.6 \%)$ when they believe that the patient needs it, and $2(1.1 \%)$ on a phone recommendation of a dentist. Only $1(0.6 \%)$ pharmacists stated he dispensed an antimicrobial without a valid prescription on demand of a patient, $1(0.6 \%)$ not to get fired, $1(0.6 \%)$ for pets, and 1 $(0.6 \%)$ for dental issue when on call.

\section{Opinions on greatest contributors to AMR}

More than half of all participants (physicians and pharmacists) considered family medicine doctors the greatest contributors to AMR $(N=216,59.8 \%)$, followed by patients $(N=175,48.5 \%)$ as presented in Table 3. Furthermore, pharmacists considered patients as the greatest contributors to AMR significantly more than physicians. On the contrary, physicians considered specialists the greatest contributors to AMR significantly more than pharmacists. Among other contributors, $3(1.7 \%)$ physicians mentioned veterinarians, 1 $(0.6 \%)$ dentists, $1(0.6 \%)$ the food industry, $1(0.6 \%)$ patient disinformation, and $1(0.6 \%)$ health system overload. Two $(1.1 \%)$ pharmacists outlined poor health care system organization, $1(0.6 \%)$ the media, $1(0.6 \%)$ veterinarians, and 1 $(0.6 \%)$ private owners of pharmacies.
Table 2. Reasons Why Physicians Are More Likely to Prescribe an Antimicrobial Without a Firm IndicATION AND Why Pharmacists ARE More Likely TO DisPENSE AN ANTIMICROBIAL Without a VAlid PRESCRIPTION

\begin{tabular}{ccc}
\hline $\begin{array}{c}\text { Physicians } \\
(N=181)\end{array}$ & $\begin{array}{c}\text { Pharmacists } \\
(\mathrm{N}=180)\end{array} \quad \mathrm{p}^{\mathrm{a}}$ \\
\hline
\end{tabular}

I prescribe

antimicrobials only

when indicated/I

dispense

antimicrobials only

with a valid

prescription

When I am not sure $76(42.0 \%) \quad$ n/a $\quad$ n/a

whether the infection

is caused by a virus

or a bacteria

If I cannot arrange follow-up with the patient

If it is for a pediatric patient

If it is the end of the working week (close to weekend)

When I do not have time to explain why the antimicrobial is not needed

When I want to keep the patient's trust

$81(44.8 \%) \quad 141(78.3 \%)<0.001$

Results are presented as numbers (proportions).

${ }^{\text {a}}$ Chi-square test or Fisher's exact test.

\section{Attitudes about $A M R$}

Most of study participants agreed with the statements, "Inappropriate use of antimicrobials causes antimicrobial resistance" (96.1\%) and "Strong knowledge of antimicrobials is important in my career" (94.2\%). Significantly more pharmacists agreed with the statement, "Antimicrobial resistance affects me and my family's health," whereas physicians were less likely to agree with the statement, "Efficacy is better if the antimicrobials are newer and more expensive." Furthermore, pharmacists greatly agreed with the statement, "Dispensing antibiotics should be more closely controlled," (91.7\%) but disagreed with the statement, "If a patient feels that he or she needs antimicrobials I will dispense them because the patient will easily obtain them at another pharmacy" (Table 4).

\section{Sources of information about AMR}

Official guidelines by professional organizations were the most frequent source of information about the use of antimicrobials and AMR for physicians (95.0\%), whereas Summary of product characteristics (SmPCs) and patient information leaflet (95\%) was most frequently used by pharmacists. Additionally, physicians significantly more often used phone apps and official guidelines by professional organizations compared with pharmacists, whereas pharmacists more frequently attended congress meetings with this topic. No significant difference was observed in the 
Table 3. Greatest Contributors to Antimicrobial Resistance According to Physicians and Pharmacists

\begin{tabular}{lcccr}
\hline & All $(\mathrm{N}=361)$ & Physicians $(\mathrm{N}=181)$ & Pharmacists $(\mathrm{N}=180)$ & $\mathrm{p}^{\mathrm{a}}$ \\
\hline Family medicine doctors & $216(59.8 \%)$ & $103(56.9 \%)$ & $113(62.8 \%)$ & 0.256 \\
Patients & $175(48.5 \%)$ & $73(40.3 \%)$ & $102(56.7 \%)$ & 0.002 \\
Specialists & $58(16.1 \%)$ & $53(29.3 \%)$ & $5(2.8 \%)$ & $<0.001$ \\
Pharmacists & $23(6.4 \%)$ & $12(6.6 \%)$ & $11(6.1 \%)$ & 0.840 \\
\hline
\end{tabular}

Results are presented as numbers (proportions).

${ }^{a}$ Chi-square test or Fisher's exact test.

frequency of consulting colleagues, using SmPCs and patient information leaflet, textbooks, or study guides and medical journals (Table 5).

\section{Beliefs about the most important causes of AMR}

Physicians most often rated not removing the focus of infection as the most important contributor to AMR (93.4\%), whereas pharmacists most frequently rated the use of antibiotics for shorter than standard duration and excessive use of antibiotics in livestock $(96.1 \%)$ as the greatest contributors to AMR. Moreover, pharmacists rated excessive use of antibiotics in livestock and empirical antibiotic therapy more frequently as an important contributor to AMR compared with physicians (Table 6).

\section{Preparedness to specific actions in practice and knowledge related to $A M R$}

Physicians were most confident in interpreting antibiograms (93.4\%). Both physicians and pharmacists felt least confident in describing the correct spectrum of different antimicrobial therapies with pharmacists feeling significantly less confident in this action compared with physicians. Physicians felt significantly better prepared for finding reliable sources of information for treating infections (Table 7). Focusing on knowledge questions, physicians scored significantly higher compared with pharmacists $(4.06 \pm 1.01$ vs. $3.71 \pm 1.08$, $p=0.001)$.

\section{Patient consultation when dispensing an antimicrobial}

All pharmacists often discussed the correct dosing and the importance of adherence to the treatment with the patient. As many as 177 (98.3\%) of them sometimes or often advised on the use of a probiotic supplement with the antibacterial treatment, $125(69.4 \%)$ discussed what to do with the leftover antimicrobials, $124(68.9 \%)$ stressed the importance of not sharing the antimicrobials with family, while $118(65.6 \%)$ sometimes or often discussed why the antimicrobial was not prescribed with the patient.

\section{Discussion}

According to this research, both physicians and community pharmacist outlined family medicine physicians as

Table 4. Physicians and Pharmacists Who Agree/Strongly Agree with Statements Regarding Attitudes About Antimicrobial Resistance

\begin{tabular}{|c|c|c|c|}
\hline & $\begin{array}{l}\text { Physicians } \\
(\mathrm{N}=181)\end{array}$ & $\begin{array}{c}\text { Pharmacists } \\
(\mathrm{N}=180)\end{array}$ & $\mathrm{p}^{\mathrm{a}}$ \\
\hline Inappropriate use of antimicrobials causes antimicrobial resistance. & $176(97.2 \%)$ & $171(95.0 \%)$ & 0.075 \\
\hline Prescribing inappropriate or unnecessary antimicrobials is professionally unethical. & $173(95.6 \%)$ & $170(94.4 \%)$ & 0.058 \\
\hline Strong knowledge of antimicrobials is important in my career. & $169(93.4 \%)$ & $171(95.0 \%)$ & 0.804 \\
\hline Antimicrobials are overused. & $168(92.8 \%)$ & $166(92.2 \%)$ & 0.840 \\
\hline $\begin{array}{l}\text { Formal teaching on proper usage of antimicrobials among health care students may } \\
\text { minimize the phenomena of antimicrobial resistance. }\end{array}$ & $168(92.8 \%)$ & $164(91.1 \%)$ & 0.021 \\
\hline $\begin{array}{l}\text { Better use of antimicrobials will reduce problems with antimicrobial-resistant } \\
\text { organisms. }\end{array}$ & $163(90.1 \%)$ & $158(87.8 \%)$ & 0.759 \\
\hline $\begin{array}{l}\text { Antimicrobial resistance will be a greater clinical problem later in my professional } \\
\text { career than it is today. }\end{array}$ & $161(89.0)$ & $157(87.2 \%)$ & 0.295 \\
\hline I would like more education on the appropriate use of antimicrobials. & $158(87.3 \%)$ & $164(91.1 \%)$ & 0.221 \\
\hline $\begin{array}{l}\text { Prescribing broad-spectrum antimicrobials when equally effective narrower } \\
\text { spectrum antimicrobials are available increases antimicrobial resistance. }\end{array}$ & $152(84.0 \%)$ & $147(81.7 \%)$ & 0.070 \\
\hline I would like more education on antimicrobial resistance. & $148(81.8 \%)$ & $165(91.7 \%)$ & 0.021 \\
\hline Antimicrobial resistance affects me and my family's health. & $140(77.3 \%)$ & $147(81.7 \%)$ & 0.004 \\
\hline Antimicrobials that I prescribe/dispense contribute to the problem of resistance. & $103(56.9 \%)$ & $113(62.8 \%)$ & 0.522 \\
\hline Appropriate use of antimicrobials can cause antimicrobial resistance. & $56(30.9 \%)$ & $57(31.7 \%)$ & 0.845 \\
\hline Efficacy is better if the antimicrobials are newer and more expensive. & $22(12.2 \%)$ & $26(14.4 \%)$ & 0.028 \\
\hline Antimicrobial resistance is not a significant problem. & $16(8.8 \%)$ & $23(12.8 \%)$ & 0.267 \\
\hline Dispensing antibiotics should be more closely controlled. & $\mathrm{n} / \mathrm{a}$ & $165(91.7 \%)$ & $\mathrm{n} / \mathrm{a}$ \\
\hline $\begin{array}{l}\text { If a patient feels that he or she needs antimicrobials, I will dispense them because the } \\
\text { patient will easily obtain them at another pharmacy. }\end{array}$ & $\mathrm{n} / \mathrm{a}$ & $3(1.7 \%)$ & $\mathrm{n} / \mathrm{a}$ \\
\hline
\end{tabular}

Results are presented as numbers (proportions).

${ }^{a}$ Chi-square test or Fisher's exact test. 
Table 5. Physicians and Pharmacists Who State They Often/Sometimes Used the Following Sources of Information About the Use of Antimicrobials and Antimicrobial Resistance

\begin{tabular}{|c|c|c|c|}
\hline & Physicians $(\mathrm{N}=181)$ & Pharmacists $(\mathrm{N}=180)$ & $\mathrm{p}^{\mathrm{a}}$ \\
\hline Official guidelines by professional organizations & $172(95.0 \%)$ & $150(83.3 \%)$ & $<0.001$ \\
\hline Patient information leaflet/Summary of product characteristics & $163(90.1 \%)$ & $171(95.0 \%)$ & 0.075 \\
\hline Colleagues & $158(87.3 \%)$ & $149(82.8 \%)$ & 0.230 \\
\hline Textbooks or study guides & $144(79.6 \%)$ & $128(71.1 \%)$ & 0.063 \\
\hline Smart phone apps & $135(74.6 \%)$ & $103(57.2 \%)$ & 0.001 \\
\hline Medical journals & $133(73.5 \%)$ & $124(68.9 \%)$ & 0.336 \\
\hline Continuous medical education courses/Congress meetings & $132(72.9 \%)$ & $154(85.6 \%)$ & 0.003 \\
\hline
\end{tabular}

Results are presented as numbers (proportions).

${ }^{a}$ Chi-square test or Fisher's exact test.

greatest contributors to the AMR $(59.8 \%)$ followed by patients $(48.5 \%)$. Although tertiary hospital-level organization is a great contributor to AMR in developed countries, ${ }^{22}$ most of the antibiotic consumption is in outpatient setting and at the primary level. In 2018, total antibiotics' expenditure in hospitals in Croatia was 17.0, compared with 1.8 defined daily dose (DDD) per 1,000 inhabitants and per day in hospitals (in EU it was 18.4 DDD per 1000 inhabitants per day). ${ }^{9,23}$ However, it remains unclear why large proportions of health care professionals (physicians and pharmacists) state that patients are the greatest contributors to AMR. One possible explanation is shifting responsibility for AMR from health sector to community or other health care workers and specialists what is consistent with previously published research. ${ }^{24}$ This is further supported with the finding that not many agreed with statements, "Antimicrobials that I prescribe/dispense contribute to the problem of resistance" and "Appropriate use of antimicrobials can cause antimicrobial resistance." A systematic review by McCullough et al. demonstrated that people believe they do not contribute to the emergence of AMR and were likely to attribute it to the actions of others. ${ }^{24}$ Furthermore, physicians, and especially pharmacists, are in a unique position to have the

\section{Table 6. Physicians and Pharmacists Who Rated EACH OF THE Following CONTRIBUTORS TO ANTIMICRObial Resistance as Very IMPORTANT/MODERATELY IMPORTANT}

\begin{tabular}{lccc}
\hline & $\begin{array}{c}\text { Physicians } \\
(\mathrm{N}=181)\end{array}$ & $\begin{array}{c}\text { Pharmacists } \\
(\mathrm{N}=180)\end{array}$ & $\mathrm{p}^{\mathrm{a}}$ \\
\hline $\begin{array}{l}\text { Not removing the focus } \\
\text { of infection }(\text { e.g., } \\
\text { catheter) }\end{array}$ & $169(93.4 \%)$ & $169(93.9 \%)$ & 0.840 \\
$\begin{array}{l}\text { Use of antibiotics for } \\
\text { shorter than standard } \\
\text { duration }\end{array}$ & $168(92.8 \%)$ & $173(96.1 \%)$ & 0.172 \\
$\begin{array}{l}\text { Use of antibiotics for } \\
\text { self-limited bacterial } \\
\text { infections }\end{array}$ & $167(92.3 \%)$ & $160(88.9 \%)$ & 0.273 \\
$\begin{array}{l}\text { Excessive use of } \\
\text { antibiotics in } \\
\text { livestock }\end{array}$ & $158(87.3 \%)$ & $173(96.1 \%)$ & 0.002 \\
$\begin{array}{l}\text { Empirical antibiotic } \\
\text { therapy }\end{array}$ & $149(82.3 \%)$ & $166(92.2 \%)$ & 0.005 \\
\hline
\end{tabular}

Results are presented as numbers (proportions).

${ }^{a}$ Chi-square test or Fisher's exact test. greatest effect on patients' adherence to treatment and lower patients' contribution to AMR. This result supports interdisciplinary approach to restraining the problem of AMR.

In this study, community pharmacists achieved significantly lower knowledge scores about AMR than physicians. This result can be explained with the fact that pharmacists in Croatia are not prescribers and the questionnaire was related to prescription-only antimicrobials (some topical antimicrobials are available over the counter). Furthermore, only a small number of pharmacists included in this study received specialist training and there was only one specialist. This, however, is representative of the structure of community pharmacists in Croatia.

Some of the community pharmacists included in this study stated that they are likely to dispense an antimicrobial without a prescription if they decide it is necessary. Some of the participants justified this practice with physicians or dentists being unavailable or with the location of their pharmacies in rural settings. However, the exact location of pharmacy was not collected in this research as it may affect the anonymity of the questionnaire. Antimicrobials (other than topical) may be dispensed only with a valid prescription in Croatia (regardless of the location of the pharmacy). ${ }^{25,26}$ There is hardly a need for over-the-counter dispensing of antimicrobials and this is supported with practices of delayed prescribing of antibiotics implemented in some countries. Family medicine physicians are encouraged to prescribe antimicrobials for respiratory symptoms only if symptoms do not subside after 3 days. ${ }^{27-33}$ Some pharmacists stated that they sometimes dispense antimicrobials without a prescription on phone request from a physician or a dentist, and a number of them dispensed antimicrobials based on the official specialist's report (before the patient acquires a valid prescription from his family medicine physician). This however, although not a rare practice, is an unfortunate example of physician's and pharmacist's collaboration and should not be done according to the current regulations. This also outlines a certain need for greater digital networking of health care system to allow patients to acquire medicines as soon as possible to stop pressuring pharmacists to dispense drugs in such cases and to discourage pharmacists from such practices.

In this study, most pharmacists agreed with the statement that dispensing of antimicrobials should be more closely monitored, while they mostly disagreed with the statement that they are likely to dispense an antimicrobial on patients request because 
Table 7. Physicians and Pharmacists Who Feel Well/Very Well Prepared for Practice Related to Antimicrobial Resistance

\begin{tabular}{lccc}
\hline & $\begin{array}{c}\text { Physicians } \\
(\mathrm{N}=181)\end{array}$ & $\begin{array}{c}\text { Pharmacists } \\
(\mathrm{N}=180)\end{array}$ & $\mathrm{p}^{\mathrm{a}}$ \\
\hline How to interpret antibiograms & $169(93.4 \%)$ & $\mathrm{n} / \mathrm{a}$ & $\mathrm{n} / \mathrm{a}$ \\
To know when to start antimicrobial therapy & $168(92.8 \%)$ & $\mathrm{n} / \mathrm{a}$ & $\mathrm{n} / \mathrm{a}$ \\
How to find reliable sources of information to treat infections & $168(92.8 \%)$ & $138(76.7 \%)$ & $<0.001$ \\
How to handle patient who demands antimicrobials & $158(87.3 \%)$ & $158(87.8 \%)$ & 0.067 \\
How to select the best antimicrobials for a specific infection & $151(83.4 \%)$ & $\mathrm{n} / \mathrm{a}$ & $\mathrm{n} / \mathrm{a}$ \\
Understand basics of antimicrobial resistance & $139(76.8 \%)$ & $140(77.8 \%)$ & 0.716 \\
To describe the correct spectrum of different antimicrobial therapies & $110(60.8 \%)$ & $80(44.4 \%)$ & 0.001 \\
\hline
\end{tabular}

Results are presented as numbers (proportions).

${ }^{a}$ Chi-square test or Fisher's exact test.

the patient can easily get the antimicrobial in an another pharmacy. These results may indicate that most pharmacists believe sometimes antimicrobials are overdispensed. It should be worth mentioning that one participant was pressured to dispense antimicrobials without a valid prescription due to the ownership structure of the pharmacy (private).

The ideal format and content of educational materials that will enable future physicians to prudently manage the use of antimicrobial drugs is not yet known. In this study, the most used sources were official guidelines and patient information leaflet or SmPCs. It would be encouraging to see greater use of medical journals as they do bring the newest knowledge and data not yet incorporated in guidelines or SmPCs. Research indicates that medical journals and other opinion leaders in the field of AMR should incorporate social media into their communication strategies to spread antimicrobial stewardship message. ${ }^{34}$ Furthermore, in this research, physicians felt the most confident in interpreting antibiograms, but the least confident in describing the correct spectrum of different antimicrobial therapies. Moreover, a German study conducted among 987 family medicine physicians showed that $50 \%$ of them were likely to prescribe an antimicrobial without a firm indication closer to weekend, ${ }^{35}$ whereas in this study, only $8.3 \%$ physicians stated the same. It is possible that this practice is more common among family medicine physicians than hospital physicians as this study included both.

This research was conducted mostly on the area of SplitDalmatia county and as such the results may not be easy generalizable. However, we believe it gives a good overview of physicians' and community pharmacists' knowledge and attitudes regarding AMR and treatment working in a similar setting. Therefore, it may be of value to similar communities. One of the limitations to the study is the fact that the preparedness for specific actions in practice was self-assessed and may represent more confidence than actual preparedness. Furthermore, formulation of some questions and statements may have led to biased answers (i.e., overprescribing), but the questionnaire was adopted from previously published studies. It is also possible that physicians and pharmacists who did not participate in the study somewhat differ from the ones who did, therefore, the study is subject to volunteer bias. The questionnaire was anonymous and participation was voluntary and without compensation so we do not expect socially desirable answers.

\section{Conclusion}

This research revealed some practices among pharmacists and physicians that should be improved and gaps in knowledge for restraining AMR of both professions. Development and utilization of rapid diagnostic tests to differ infections of viral and bacterial etiology is needed as "unsure whether it is viral or bacterial infection" seems to be one of the main reasons for prescribing an antimicrobial when not indicated. Furthermore, it also revealed that health care workers tend to shift responsibility for AMR to patients. More attention should be given to patient consultation when dispensing and prescribing an antimicrobial as this may reduce their contribution to AMR. Our findings are consistent with previous research and support the conclusion that the fundamental elements of AMR management deserve more attention.

\section{Acknowledgment}

The authors thank Dalibora Behmen, MA, for proofreading this article.

\section{Disclosure Statement}

All authors declare no competing interests.

\section{Funding Information}

No funding was received for this research.

\section{References}

1. World Health Organization. 2019. Ten threats to global health in 2019. Available at https://www.who.int/newsroom/feature-stories/ten-threats-to-global-health-in-2019 (accepted May 20, 2020).

2. Review on Antimicrobial Resistance. 2016. Tackling drugresistant infections globally: final report and recommendations. Available at https://amr-review.org/sites/default/ files/160518_Final\%20paper_with\%20cover.pdf (accessed May 23, 2020).

3. Rathish, D., and N.D. Wickramasinghe. 2020. Prevalence, associated factors and reasons for antibiotic self-medication among dwellers in Anuradhapura: a community-based study. Int. J. Clin. Pharm. 42:1139-1144.

4. Hu, X.Y., M. Logue, and N. Robinson. 2020. Antimicrobial resistance is a global problem-a UK perspective. Eur. J. Integr. Med. 36:101136. 
5. Lecky, D.M., S. Granier, R. Allison, N.Q. Verlander, S.M. Collin, and C. McNulty. 2020. Infectious disease and primary care research-what English general practitioners say they need. Antibiotics (Basel) 9:E265.

6. Hammond, A., B. Stuijfzand, M.B. Avison, and A.D. Hay. 2020. Antimicrobial resistance associations with national primary care antibiotic stewardship policy: primary care-based, multilevel analytic study. PLoS One 15: e0232903.

7. Jukic, I., D. Rusic, J. Vukovic, P.M. Zivkovic, J. Bukic, D. Leskur, A. Seselja Perisin, M. Luksic, and D. Modun. 2020. Correlation of registered drug packs with Maastricht V/Florence Consensus Report and national treatment guidelines for management of Helicobacter pylori infection. Basic Clin. Pharmacol. Toxicol. 126:212-225.

8. Rusic, D., J. Bozic, J. Bukic, A. Seselja Perisin, D. Leskur, D. Modun, and S. Tomic. 2019. Evaluation of accordance of antibiotics package size with recommended treatment duration of guidelines for sore throat and urinary tract infections. Antimicrob. Resist. Infect. Control 8:30.

9. European Centre for Disease Prevention and Control. 2020. Antimicrobial consumption. Available at https://www.ecdc .europa.eu/en/antimicrobial-consumption (accessed May 16, 2020).

10. Hsu, J. 2020. How covid-19 is accelerating the threat of antimicrobial resistance. BMJ 369: https://doi.org/10.1136/ bmj.m1983 (accessed October 9, 2020).

11. Rawson, T.M., L. Moore, E. Castro-Sanchez, E. Charani, F. Davies, G. Satta, M.J. Ellington, and A.H. Holmes. 2020. COVID-19 and the potential long-term impact on antimicrobial resistance. J Antimicrob. Chemother. 75:16811684.

12. Dyar, O.J., G. Tebano, nd C. Pulcini; ESGAP (ESCMID Study Group for Antimicrobial stewardshiP). 2017. Managing responsible antimicrobial use: perspectives across the healthcare system. Clin. Microbiol. Infect. 23: 441-447.

13. Garau, J., and M. Bassetti. 2018. Role of pharmacists in antimicrobial stewardship programmes. Int. J. Clin. Pharm. 40:948-952.

14. Hernandez-Santiago, V., P.G. Davey, D. Nathwani, C.A. Marwick, and B. Guthrie. 2019. Changes in resistance among coliform bacteraemia associated with a primary care antimicrobial stewardship intervention: a population-based interrupted time series study. PLoS Med. 16:e1002825.

15. Singer, A., S. Fanella, L. Kosowan, J. Falk, B. Dufault, K. Hamilton, and A. Walus. 2018. Informing antimicrobial stewardship: factors associated with inappropriate antimicrobial prescribing in primary care. Fam. Pract. 35:455460.

16. Rusic, D., J. Bozic, M. Vilovic, J. Bukic, P.M. Zivkovic, D. Leskur, A. Seselja Perisin, S. Tomic, and D. Modun. 2018. Attitudes and knowledge regarding antimicrobial use and resistance among pharmacy and medical students at the University of Split, Croatia. Microb. Drug Resist. 24:15211528.

17. Teixeira Rodrigues, A., M. Ferreira, M. Piñeiro-Lamas, A. Falcão, A. Figueiras, and M.T. Herdeiro. 2016. Determinants of physician antibiotic prescribing behavior: a 3 year cohort study in Portugal. Curr. Med. Res. Opin. 32:949957.

18. Teixeira Rodrigues, A., M. Ferreira, F. Roque, A. Falcão, E. Ramalheira, A. Figueiras, and M.T. Herdeiro. 2016.
Physicians' attitudes and knowledge concerning antibiotic prescription and resistance: questionnaire development and reliability. BMC Infect. Dis. 16:7.

19. Smith, C.R., L. Pogany, S. Foley, J. Wu, K. Timmerman, M. Gale-Rowe, and A. Demers. 2017. Canadian physicians' knowledge and counseling practices related to antibiotic use and antimicrobial resistance: two-cycle national survey. Can. Fam. Physician 63:e526-e535.

20. Zhuo, A., M. Labbate, J.M. Norris, G.L. Gilbert, M.P. Ward, B.V. Bajorek, C. Degeling, S.J. Rowbotham, A. Dawson, K.A. Nguyen, G.A. Hill-Cawthorne, T.C. Sorrell, M. Govendir, A.M. Kesson, J.R. Iredell, and D. Dominey-Howes. 2018. Opportunities and challenges to improving antibiotic prescribing practices through a One Health approach: results of a comparative survey of doctors, dentists and veterinarians in Australia. BMJ Open 8:e020439.

21. Roque, F., S. Soares, L. Breitenfeld, A. Figueiras, and M.T. Herdeiro. 2015. Influence of community pharmacists' attitudes on antibiotic dispensing behavior: a cross-sectional study in Portugal. Clin. Ther. 37:168-177.

22. Chokshi, A., Z. Sifri, D. Cennimo, and H. Horng. 2019. Global contributors to antibiotic resistance. J. Glob. Infect. Dis. 11:36-42.

23. European Centre for Disease Prevention and Control. 2020. Antimicrobial consumption in the EU/EEA, 2018. Available at https://www.ecdc.europa.eu/sites/default/files/documents/ Antimicrobial-consumption-EU-EEA.pdf (accessed May 19, 2020).

24. McCullough, A.R., S. Parekh, J. Rathbone, C.B. Del Mar, and T.C. Hoffmann. 2016. A systematic review of the public's knowledge and beliefs about antibiotic resistance. J. Antimicrob. Chemother. 71:27-33.

25. The Agency for Medicinal Products and Medical Devices. 2020. Medicinal Products Database. Available at http:// www.halmed.hr/en/Lijekovi/Baza-lijekova (accessed May 26, 2020).

26. Ministry of Health of the Republic of Croatia. Ordinance on the criteria for the classification of medical products and on the prescribing and dispensing of prescription medical products. [translated from Croation]. Available at https://narodne-novine .nn.hr/clanci/sluzbeni/2013_07_86_1937.html (accessed May 26, 2020).

27. Stuart, B., H. Hounkpatin, T. Becque, G. Yao, S. Zhu, P. Alonso-Coello, A. Altiner, B. Arroll, D. Böhning, J. Bostock, H. Bucher, M. de la Poza, N.A. Francis, D. Gillespie, A.D. Hay, T. Kenealy, C. Löffler, G. Mas-Dalmau, L. Muñoz, K. Samuel, M. Moore, and P. Little. 2019. Delayed antibiotic prescribing for respiratory tract infections: protocol of an individual patient data meta-analysis. BMJ Open 9:e026925.

28. Spurling, G.K., C.B. Del Mar, L. Dooley, R. Foxlee, and R. Farley, R. 2013. Delayed antibiotics for respiratory infections. Cochrane Database Syst. Rev. 9: CD004417.

29. Dallas, A., A. Davey, K. Mulquiney, J. Davis, P. Glasziou, M. Van Driel, and P. Magin. 2020. Delayed prescribing of antibiotics for acute respiratory infections by GP registrars: a qualitative study. Fam. Pract. 37:406411.

30. Ryves, R., C. Eyles, M. Moore, L. McDermott, P. Little, and G. M. Leydon. 2016. Understanding the delayed prescribing of antibiotics for respiratory tract infection in 
primary care: a qualitative analysis. BMJ Open 6: e011882.

31. Avent, M.L., J. Fejzic, and M.L. van Driel. 2018. An underutilised resource for Antimicrobial Stewardship: a 'snapshot' of the community pharmacists' role in delayed or 'wait and see' antibiotic prescribing. Int. J. Pharm. Pract. 26:373-375.

32. Seipel, M., E.S. Prohaska, J.F. Ruisinger, and B.L. Melton. 2019. Patient knowledge and experiences with antibiotic use and delayed antibiotic prescribing in the outpatient setting. J. Pharm. Pract. [Epub ahead of print]; DOI: 10.1177/0897190019889427.

33. Saha, S.K., L. Hawes, and D. Mazza. 2018. Improving antibiotic prescribing by general practitioners: a protocol for a systematic review of interventions involving pharmacists. BMJ Open 8:e020583.

34. Cumbraos-Sánchez, M.J., R. Hermoso, D. Iñiguez, J.R. Paño-Pardo, M.Á. Allende Bandres, and M.P. Latorre Martinez. 2019. Qualitative and quantitative evaluation of the use of Twitter as a tool of antimicrobial stewardship. Int. J. Med. Inform. 131:103955.

35. Salm, F., S. Schneider, K. Schmücker, I. Petruschke, T.S. Kramer, R. Hanke, C. Schröder, C. Heintze, U. Schwantes, P. Gastmeier, and J. Gensichen; RAI-Study Group. 2018. Antibiotic prescribing behavior among general practitionersa questionnaire-based study in Germany. BMC Infect. Dis. 18:208.

Address correspondence to: Josko Bozic, MD, PhD Department of Pathophysiology University of Split School of Medicine Soltanska 2 21000 Split

Croatia

E-mail: josko.bozic@mefst.hr 